Rev Inv Vet Perú 2000; 11(2):6-23

\title{
ADENOMATOSIS PULMONAR OVINA: EVIDENCIAS DE INMUNOSUPRESION RETROVIRAL*
}

\author{
Raúl Rosadio A. ${ }^{1}$ y Michael Sharp ${ }^{2}$
}

\section{Whitroct}

Monoclonal antibodies have been used to characterize peripheral and pulmonary leukocytes (bronchoalveolar lavage cells) derived from naturally affected and experimentally induced sheep pulmonary adenomatosis (SPA, Jaagsiekte, ovine pulmonary carcinoma) cases. Hematological parameters of peripheral blood from SPA affected animals $(\mathrm{n}=10)$ showed marked lymphopenia $\left(2.66 \pm 1.36 \times 10^{3} \mathrm{~mL}^{-1}, \mathrm{p}<0.05\right)$ and neutrophilia $\left(7.96 \pm 3.84 \times 10^{3} \mathrm{~mL}^{-1}, \mathrm{p}<0.05\right)$ when compared to non-SPA animals $(\mathrm{n}=6)$. The peripheral lymphopenia was characterized by a significant reduction in number and proportions of $\mathrm{CD} 5+$ and major histocompatibility complex (MHC) class-II-restricted $(\mathrm{CD} 4+)$ T lymphocytes $(\mathrm{p}<0.05)$, as well as a significant increase in the proportions of MHC class-I-restricted (CD8+) and B (sIgG+, CD45RA+) lymphocytes when compared to non-SPA cases $(\mathrm{n}=5)(\mathrm{p}<0.5)$. Similar lymphopenia and significant reduction of CD5+, $\mathrm{CD} 2+$ and $\mathrm{CD} 4+$ in peripheral blood was also observed in experimentally-induced SPA lambs showing severe SPA lesions 5-10 weeks post inoculation. The lymphoid alterations observed in these lambs was reflected in significant reduction of lymphoid tissue weight as well as severe lymphoid cellular depletion in the cortical thymus and $2 / 2$ splenic follicles and periarteriolar lymphoid sheath. The affected lambs also slowed evidence of accelerated involutive process of severely affected thymus. Evaluation of BAL samples from SPA affected lungs $(n=9)$, showed a 24 -fold increase in total leukocytes and alveolar macrophages, a 185 -fold increase in polymorphonuclear cells, and an 11 -fold increase in lymphocytes. The influx of lymphoid cells into SPA affected lungs was accompanied by significantly decreased proportions of CD5+ and CD4+, paralleled with an increased proportion of CD8+ lymphocytes $(\mathrm{p}<0.05)$. Alteration of the $\mathrm{CD} 4+/ \mathrm{CD} 8+$ ratio was observed in both peripheral (from 3.9 in non-SPA to 1.4 in SPA) and pulmonary lymphocytes (from 4.9 in non-SPA to 2 in SPA). The vast influx of lymphoid cells into the affected lung tissue may well reflect part of the host's immune response against viral infection and/or transformed cells. However, the marked reduction in number and proportion of MHC class-II-restricted peripheral $\mathrm{CD} 4+\mathrm{T}$ cells, as well as the increase in the proportions of MHC class-I- restricted CD8+ T and sIgG+ B cells in peripheral lymphocytes, suggests the existence of previously unrecognized immune dysfuntions similar to those reported in retrovirus-induced human and feline immunosuppressive diseases.

Key words : Ovine pulmonary adenomatosis, Ovine pulmonary carcinoma, Immune dysfunctions, immusupression.

\footnotetext{
* Trabajo presentado a la Academia Peruana de Ciencias Veterinarias.

'IVITA - Facultad de Medicina Veterinaria, UNMSM. E.mail:rrosadio@terra.com.pe

${ }^{2}$ Moredun Research Institute, Edinburgo, Escocia, Gran Bretaña
} 


\section{Pestiven}

Un panel de anticuerpos monoclonales específicos para subpoblaciones linfoides fueron usados para caracterizar leucocitos periféricos y pulmonares derivados de animales clínicamente enfermos $(n=10)$ y corderos experimentalmente infectados $(n=9)$ con el retrovirus productor de la adenomatosis pulmonar ovina (APO). Parámetros hematológicos de sangre periféricas de animales afectados naturalmente mostraron una clara linfopenia $\left(2.66 \pm 1.36 \times 10^{3} \mathrm{~mL}^{-1}, \mathrm{p}<0.05\right)$ y neutrofilia $\left(7.96 \pm 3.84 \times 10^{3} \mathrm{~mL}^{-1}, \mathrm{p}<0.05\right)$ comparado con animales controles $(n=6)$. La linfopenia periférica en estos animales se caracterizó por una reducción significativa en el número y proporciones de linfocitos $T$ $\mathrm{CD} 5+$ y $\mathrm{CD} 4+$, observándose paralelamente un incremento significativo en las proporciones de células $C D 8+y$ linfocitos $B(C D 45 R A+y$ slgG +$)$. Similares linfopenia y reducciones significativas de $\mathrm{CD} 5+, \mathrm{CD} 2+\mathrm{y} \mathrm{CD} 4+$ en sangre periférica fueron observadas en corderos experimentalmente infectados y que desarrollaron severas lesiones de la enfermedad a las 5-10 semanas pos inoculación. Los animales clínicamente enfermos mostraron alteraciones en la relación $\mathrm{CD} 4+/ \mathrm{CD} 8+$ circulante, disminuyendo desde 3.9 en animales no afectados con APO a 1.4 en animales afectados con APO. Las alteraciones linfoides en los corderos produjeron reducciones significativas en el peso de tejidos linfoides principalmente en el timo de animales infectados y severa despoblaciones de células linfoide en la corteza tímica así como en $2 / 2$ nódulos y manto periarteriolar esplénico. También se observó una evidencia de un acelerado proceso involutivo del timo de corderos infectados. Evaluaciones de lavados pulmonares en ambos tipos de animales infectados mostraron un incremento significativo de células leucocitarias presentes en fluidos pulmonares recuperados. Los animales clínicamente enfermos mostraron un significativo aumento en células totales y macrófagos alveolares ( 24 veces), neutrófilos ( 185 veces) y linfocitos (11 veces) comparados con animales controles. A pesar de este enorme flujo celular hacia pulmones neoplásicos, se detectó una significativa reducción en las proporciones de linfocitos T CD5+ y CD4+ así como una elevada proporción de $\mathrm{CD} 8+(\mathrm{p}<0.05)$. Las muestras de lavados pulmonares de corderos severamente infectados (5/9 mostraron también un aumento de células totales (11 veces), macrófagos y linfocitos ( 8 veces) comparados a corderos de edades similares $(n=7)$. En estos corderos, sin embargo, hubo solamente una reducción en las proporciones de células $B$ (CD45RA+y sIgG + ) pulmonares. El gran flujo celular hacia pulmones afectados tal vez refleje parte de la respuesta inmune del hospedero hacia la infección viral y/o células transformadas. Sin embargo, la severa reducción en número y proporciones de linfocitos $\mathrm{T}$ CD4+ asi como el incremento en las proporciones de linfocitos CD8 y células B en linfocitos periféricos observadas principalmente en animales naturalmente enfermos con APO sugiere la existencia de disfunciones inmunes similares a las reportadas en infecciones retrovirales humanas y felinas.

Palabras clave: Adenomatosis pulmonar ovina, carcinoma pulmonar ovina, disfunción inmune, inmunosupresión.

\section{mingtin}

La adenomatosis pulmonar ovina (APO) es una enfermedad altamente transmisible, responsable de alta mortalidad en la crianza ovejera en muchos países del mundo incluyendo el Perú (De Martini et al., 1988). La enfermedad fue diagnosticada con características epizoóticas en la sierra central del Perú en 1945 (Cuba Caparó, 1945), permaneciendo en forma enzoótica en la sierra central y difundiéndose a nivel nacional a partir de los 1980s (Rosadio, 1991). Esta enfermedad neoplásica, denominada también Carcinoma pulmonar ovino o Jaagsiekte, afecta principalmente a epitelios alveolares (Neumocitos Tipo II) o bronquiolos terminales (Células Clara) por lo que debe describirse como carcinoma bronquioalveolar (De Martini et al., 1988). Los animales 
afectados, generalmente adultos, pierden peso progresivamente, tosen frecuentemente y cuando son levantados de los miembros posteriores exhiben secreción nasal acuosa (Sharp, 1987). Esta secreción nasal (fluido pulmonar), al parecer proveniente de las células transformadas, contiene células neoplásicas exfoliadas, células inflamatorias y abundante cantidad de material infeccioso (Sharp et al., 1983; Rosadio et al., 1988a).

Desde las investigaciones iniciales se sospechó de una etiología viral. Inicialmente se postuló el rol etiológico de un herpesvirus ovino aislado de macrófagos alveolares procedentes de animales infectados (Sharp, 1987), pero tuvo que ser descartado al no reproducirse la enfermedad (Sharp, 1987). Posteriormente, se identificaron, por microscopía electrónica, partículas retrovirales íntimamente asociadas a tejidos tumorales (Sharp et al., 1983) y se detectó una enzima exclusiva de los retrovirus (transcriptasa reversa) en pulmones y fluidos pulmonares infectados (Herring et al., 1983; De Martini et al., 1987).

La teoría retroviral se consolidó al reproducirse experimentalmente la enfermedad, utilizando material conteniendo la enzima transcriptasa reversa, en animales neonatos (Herring et al., 1983; Rosadio et al., 1988b). El retrovirus presente en tejido y fluidos infectados contiene proteínas virales (cápside y nucleocápside) identificadas mediante antisueros de retrovirus del prototipo $\mathrm{D}$ de monos (Mason-Pfizer monkey virus) y el B murino (tumor mamario del ratón) (Sharp et al., 1983; Sharp, 1987; Rosadio et al., 1988a). Sin embargo, la imposibilidad de tener sistemas convencionales de aislamientos virales ha limitado una detallada caracterización viral así como impedido el desarrollo de pruebas diagnósticas necesarias para el monitoreo inmunológico y/o infección viral.

Existe muy poca información sobre la patogénesis viral en esta enfermedad. Se desconoce, por ejemplo, los sitios iniciales de replicación y/o amplificación viral y sobre todo mecanismos oncogenéticos que conducen a la transformación epitelial. El presente artículo presenta evidencias que los animales clínicamente enfermos por APO y corderos experimentalmente infectados muestran evidencias de alteraciones linfoides caracterizadas por: linfopenia circulante y alteraciones en ciertas subpoblaciones linfoides fundamentalmente una linfocitopenia de $\mathrm{CD} 4+$. Paralelamente, se observan aumento de linfocitos B circulantes asociado con hipergarnmaglobulinemia en animales clínicamente enfermos y una elevada respuesta mitogénica al lipopolisacarido (LPS) en 3/3 animales estudiados. La reproducción experimental en corderos ocasiona similares tendencias de CD4 linfocitopenia y principalmente una severa depleción linfoide en timo y bazo de los corderos severamente afectados de APO.

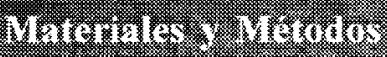

\section{Animales naturalmente enfermos con APO}

Se utilizaron dieciséis borregas padeciendo clínicamente de procesos neumónicos crónicos. Estos animales procedentes de establecimientos ovejeros del Norte Este y/o Oeste, Escocia y de distintas razas escocesas (Scottish Black Face $n=5$, Greyface $n=7$ $y$ otros $n=4$ ) fueron conducidos al Instituto de Moredun, Edinburgo. Los animales fueron sometidos a exámenes clínicos incluyendo prueba de la carretilla para comprobar presencia de secreción pulmonar. A todos los animales se les extrajo muestras de sangre para realizar recuentos totales y diferenciales sanguíneos así como pruebas serológicas para confirmar negatividad a infecciones lentivirales (Maedi/Visna). Diez de estos animales fueron diagnosticados estar afectados por APO y los otros 8 padeciendo diferentes procesos respiratorios crónicos pero no APO. 


\section{Reproducción experimental de la enfermedad en corderos neonatos}

Para la reproducción de la enfermedad se utilizaron corderos de un día de nacido de las razas Scottish Grayface y cruces comerciales. Los corderos $(n=9)$ fueron infectados por vía intratraqueal con inóculos preparados de fluidos pulmonares procedentes de animales infectados con APO. El material infectante fue clarificado a $10000 \mathrm{x}$ g por $10 \mathrm{~min}$. a $4^{\circ} \mathrm{C}$ y ultracentrifugado en $50 \%$ de glicerol en TNE (10mM Tris-HCL, $100 \mathrm{mM}$ de CINa y $1 \mathrm{mM}$ de EDTA) a 100 $000 \times$ g por $60 \mathrm{~min} . \mathrm{a} 4^{\circ} \mathrm{C}$. El pellet resultante fue resuspendido en $5 \mathrm{ml}$ de TNE ( $15 \mathrm{ve}$ ces concentrado) y utilizado como una dosis de inoculación. Al momento de inocular la dosis infectante a un cordero, se inoculó simultáneamente a otro animal con suero fisiológico estéril (pareja control). Todos los corderos infectados fueron mantenidos con sus madres respectivas en un corral físicamente separados del grupo control hasta que comenzaron ha desarrollar cuadros de deficiencias respiratorias o sacrificados al término del experimento. Todos los animales fueron sangrados antes de sacrificio y las muestras sanguíneas procesadas de manera similar que los animales adultos. Al momento de sacrificio de un cordero afectado se procedió al sacrificio de un cordero del grupo control de edad similar al infectado. Dos animales fueron sacrificado al término del experimento (25-27 semanas post inoculación) sin presentar sintomatología que evidenciara disfunción respiratoria.

\section{Exámenes macroscópico e histopato- lógico}

Todos los animales utilizados en el presente estudio fueron sacrificados utilizando sobredosis de pentobarbital sódico (Euthatal, BMB Animal Health Ltda, UK) para realizar exámenes de necropsia en busca de lesiones compatibles con APO. Después de proceder con el lavado de pulmón derecho, se tomaron muestras de tejido pulmonar afectado, nódulos linfáticos regionales (mediastínicos y bronquiales) y/o tejido linfoide (timo, bazo) en los corderos. Los diversos tejidos fueron fijados en solución formol buferado al $10 \%$, procesadas y reducidas a grosores de $5 \mathrm{~mm}$ y coloreadas con H\&E. Las lesiones neumónicas crónicas y/ o neoplásica fueron definidas y ranqueadas de acuerdo a lo previamente descrito (Rosadio et al., 1988 a y b; Lairmore et al., 1986).

\section{Preparaciones celulares}

Las muestras sanguíneas fueron obtenidas por punción yugular en tubos al vacío heparinados (Becton and Dickinson, CA). El recuento de células leucocitarias sanguineas fue realizado en un contador de células (Coulter cell counter, Coulter Electronic, Luton) usando una sonda con $100 \mathrm{~mm}$ de apertura. El recuento diferencial fue realizado en impresiones sanguíneas coloreadas con Leishman de acuerdo a las características morfológicas leucocitarias. Para el fenotipado, las muestras sanguíneas fueron centrifugadas en $10 \mathrm{ml}$ de Lymphoprep (Nycomed Pharma, Oslo, Norway) a 3000 rpm durante 40 minutos. La banda correspondiente fue lavada dos veces con PBS-A y ajustada a concentración de $10^{8}$ células $\mathrm{ml}^{-}$ ' usando PBS-A.

Después de recuperar la capa de linfocitos, ésta fue lavada dos veces con la solución Hanks conteniendo $10 \%$ de seroalbúmina (BSA) y $0.5 \%$ heparina. Finalmente, el pellet, ajustado a $10^{7}-10^{8}$ células $\mathrm{ml}^{-1}$, fue resuspendido en PBS conteniendo $1 \%$ BSA, $0.5 \%$ heparina y $0.1 \%$ azida sódica (PBS-A) y quedar listo para el fenotipado.

Los lavados pulmonares fueron realizados en el pulmón derecho utilizando $1.0 \mathrm{~L}$ (solución Hanks salina tamponeada estéril conteniendo $1 \%$ de penicilina, $\mathrm{pH}$ 7.2) en animales adultos y $0-5 \mathrm{~L}$ en corderos de acuerdo a descripciones anteriores (Burrells, 1985). Después de lavar los lóbulos del pulmón derecho, el fluido fue clarificado a través de 
doble gasa y centrifugado a $200 \mathrm{x}$ g por 10 $\mathrm{min}$. El pellet resultante fue lavado dos veces en solución Hanks al $10 \%$ enriquecido con suero de ternero y $0.5 \%$ de heparina. El recuento total y la viabilidad celular (determinado por exclusión de azul de tripano) fueron realizados en hemocitómetros y las células identificadas observando características morfológicas en coloraciones Leishman's. Para los análisis de fenotipado, 4-6 $\times 10^{8}$ células fueron puestas en la parte superior de $25 \mathrm{mls}$ de solución al $50 \%$ de stock percoll isotónica (Sigma) y separadas por centrifugación a $10000 \mathrm{xg}$ por $30 \mathrm{~min}$. a $5^{\circ} \mathrm{C}$.

\section{Marcado con immunofluorescencia y citometría de flujo}

Anticuerpos monoclonales (AcMo) específicos contra antígenos superficiales de linfocitos ovinos (Mackay, 1988; Hein and Mackay, 199lb, (Cuadro 1) fueron utilizados para identificar subpoblaciones de linfocitos, y localizar antígenos de histocompatibilidad mayor (MHC) expresados en linfocitos. Las células fueron marcadas incubando $50 \mu \mathrm{l}$ conteniendo $5 \times 10^{6}$ leucocitos con $50 \mu 1$ de un AcMo diluidas óptimamente durante $30 \mathrm{~min}$ a $4^{\circ} \mathrm{C}$. Las células lavadas dos veces con PBS-A fueron incubadas con $50 \mu \mathrm{l}$ de suero anti-ratón marcado con fluoresceína (dilución 1:40 en PBS). Después de lavar dos veces con PBS-A, las células finalmente fueron resuspendidas en $500 \mu \mathrm{l}$ de fijador $(2 \%$ paraformaldehido en PBS) y guardadas a $4^{\circ} \mathrm{C}$ en la oscuridad. Las células marcadas fueron analizadas usando un analizador celular activado por fluorescencia (FACS IV, Becton Dickinson, Mountain View, CA). Las células muertas fueron excluidas de acuerdo a su tamaño celular utilizando adecuadamente los separadores de campo y las células no linfoides eliminadas de acuerdo a la apariencia granular (Burrells et al., 1989). El porcentaje de células correctamente marcadas fue determinado identificando los márgenes mínimos utilizando valores de fondo obtenidos con muestras carentes de anticuerpo monoclonal o el anticuerpo secundario (anti-ratón marcado con fluoresceína). Finalmente se analizaron un total de $10^{4}$ linfocitos por muestra por el FASC utilizando rayos argón láser programado a $400 \mathrm{mV}, 488 \mathrm{~nm}$ (adecuada excitación del FITC) y un voltaje fotomultiplicador de $650 \mathrm{~V}$.

Cuadro 1. Especificidad de los anticuerpos monoclonales dirigidos contra antígenos superficiales de las células leucocitarias del ovino

\begin{tabular}{|c|c|c|}
\hline $\begin{array}{l}\text { Antígeno de superficie } \\
\text { celular }\end{array}$ & $\begin{array}{l}\text { Anticuerpo, } \\
\text { clon }\end{array}$ & Especificidad \\
\hline CD45 LCA & $1-32$ & Leucocitos periféricos \\
\hline CD45RA & $20-96$ & $\begin{array}{l}\text { Principalmente en Células B y subpoblaciones } \\
\text { inmaduras de Células T. }\end{array}$ \\
\hline CD5 (SBU-T1) & $25-91$ & Todas las células $T$, baja expresión en células $B$ \\
\hline $\mathrm{CD} 2$ & $36 \mathrm{~F}$ & Toda célula $T$ con receptores $\alpha \beta$ \\
\hline CD4 (SBU-T4) & $44-38$ & Linfocitos $\mathrm{T}$ auxiliar \\
\hline CD8 (SBU-T8) & $38-65$ & Linfocitos T citotóxico/supresor \\
\hline$\gamma \delta \mathrm{TcR}(\mathrm{SBU}-\mathrm{T} 19)$ & 86 & Linfocitos T, CD4, CD8 \\
\hline MHC clase I & $41-19$ & Mayoría de células somáticas \\
\hline MHC clase II & $28-1$ & Linfocitos B y Linfocitos $T$ activados \\
\hline IgG, cadena ligera & VPM 8 & Linfocitos B periféricos \\
\hline
\end{tabular}




\section{Análisis estadístico}

El porcentaje de las células identificadas positivamente por los diferentes anticuerpos monoclonales fue utilizado para calcular números absolutos usando los datos sobre recuentos totales y diferenciales. Los resultados se expresan como promedios de números absolutos $\times 10^{3} \mathrm{ml}^{-1}$ de sangre circulante y $\times 10^{5}$ células $\mathrm{ml}^{-1}$ de fluido de lavado pulmonar \pm una desviación estándar. Los valores del número de subpoblaciones linfoides así como el número de linfocitos totales para cada animal fueron utilizados para determinar las proporciones de las diferentes subpoblaciones de linfocitos. La prueba no paramétrica de Mann-Whitney fue usada para comparar los valores promedios obtenidos en animales afectados y no afectados por APO. Similarmente, fueron usados para comparar los valores encontrados en corderos experimentalmente inducidos con la enfermedad versus los controles.

\section{Resultatios}

Todos las borregas padeciendo APO se encontraban moderada a severamente emaciadas mostrando severas dificultades respiratorias. De estos animales se recuperaron un promedio de $0.3 \mathrm{~L}(0.1-1.0 \mathrm{~L})$ de fluido pulmonar al momento de la necropsia. Los exámenes histopatológicos revelaron lesiones típicas de APO, caracterizadas por presencia de proliferaciones neoplásicas epiteliales formando patrones clásicos acinares en forma multifocales o diseminadas. Se observaron, además, un rango de leve a moderadas infiltraciones mononucleares y células plasmáticas peribronquiolares y/o perivasculares. Los animales clasificados como no afectados por APO mostraron igualmente moderada a severa emaciación y mostraron lesiones neumónicas que variaron desde consolidaciones grisáceas discretas focales hasta multifocales. Los exámenes histopatológicos de estos pulmones revelaron neumopatías variadas desde leves a moderadas neumonías intersticiales linfoides (NIL) hasta neumonía granulomatosa focal y aún lesiones de NIL con severa y difusa fibromuscular hiperplasia, pero ninguna evidencia de APO. En cuatro de estos casos la patología pulmonar estuvo asociada con neumonía parasitaria.

Ocho de nueve corderos neonatos inoculados experimentalmente desarrollaron la enfermedad. Cinco de estos 8 animales presentaron severas lesiones neoplásicas y fueron sacrificados entre 5-10 semanas post-inoculación (Cuadro 2). Los 3 restantes fueron catalogados en tener leve $(n=1)$ y moderadas $(n=2)$ alteraciones tumorales y con excepción de uno, todos fueron sacrificados entre 17-27 semanas. El animal que no desarrolló lesiones tuvo que ser sacrificado a las 25 semanas post-infección experimental sin presentar alteraciones clínicas de la enfermedad.

Los parámetros hematológicos de los leucocitos circulantes periféricos de los animales clínicamente afectados por APO, mostraron alteraciones en el total de células totales y en los recuentos diferenciales. En los animales afectados por APO el número de leucocitos totales estuvieron elevados pero con clara predominancia de células neutrófílicas (7.96 $\pm 3.84 \times 10^{3} \mathrm{ml}^{-1}, \mathrm{p}<0.05$ ). El recuento linfocitario en estos animales mostró una reducción significativa de los leucocitos circulante $\left(2.66 \pm 1.3610^{3} \mathrm{ml}^{-1}, \mathrm{p}<\right.$ 0.001 )(Figura la). La reducción de linfocitos sanguíneos circulantes estuvo asociado con una disminución significativa de células identificadas con anticuerpos monoclonales CD5+ $(\mathrm{p}=0.03), \mathrm{CD} 2+(\mathrm{p}=0.05), \mathrm{yCD} 4+(\mathrm{p}=0.05)$ (Figura la y 1b). Las células que expresan $\mathrm{CD} 8+(\mathrm{p}=0.3), \delta \gamma \mathrm{TCR}+(\mathrm{p}=0.7), \mathrm{sIgG}+$ $(\mathrm{p}=0.1)$ no se observaron disminuidas (Figura la y $1 b$ ). En el análisis de las proporciones se observó, además un aumento significativo en las proporciones de células identificadas por el CD45RA $+(p=0.02)$ y sIgG + $(\mathrm{p}=0.05)$, observándose paralelamente una disminución de las células CD4+ $(p=0.05)$ (Figura 2). El aumento significativo de proporciones de linfocitos $B$ circulantes que 
Cuadro 2. Corderos utilizados en la reproducción experimental de APO.

\begin{tabular}{lll}
\hline Cordero $\mathrm{N}^{\circ}$ & Edad de sacrificio & $\begin{array}{l}\text { Lesiones histopatológicas } \\
(\mathrm{APO})^{*}\end{array}$
\end{tabular}

Severamente afectados : $(n=5)$

0232

1299

5 sem

$++++$

1323

$6 \mathrm{sem}$

$++++$

0369

9 sem

$++++$

0231

9 sem

$++++$

10 sem

$++++$

Leve-moderamente afectados : $(n=4)$

1300

1322

0374

5 sem

0233

$17 \mathrm{sem}$

25

27 sem

$$
\begin{aligned}
& ++ \\
& ++ \\
& -- \\
& +
\end{aligned}
$$

Controles : $(\mathrm{n}=7)$

$\begin{array}{lll}1351 & 5 \mathrm{sem} & -- \\ 1352 & 6 \mathrm{sem} & -- \\ 0229 & 9 \mathrm{sem} & - \\ 0508 & 10 \mathrm{sem} & - \\ 0090 & 17 \mathrm{sem} & - \\ 0509 & 25 \mathrm{sem} & -\end{array}$

* Grados de lesiones de APO: Severo $(+++/+++)$, moderado $(++)$, ligero $(+)$ y $\sin$ lesiones neoplásicas (-)

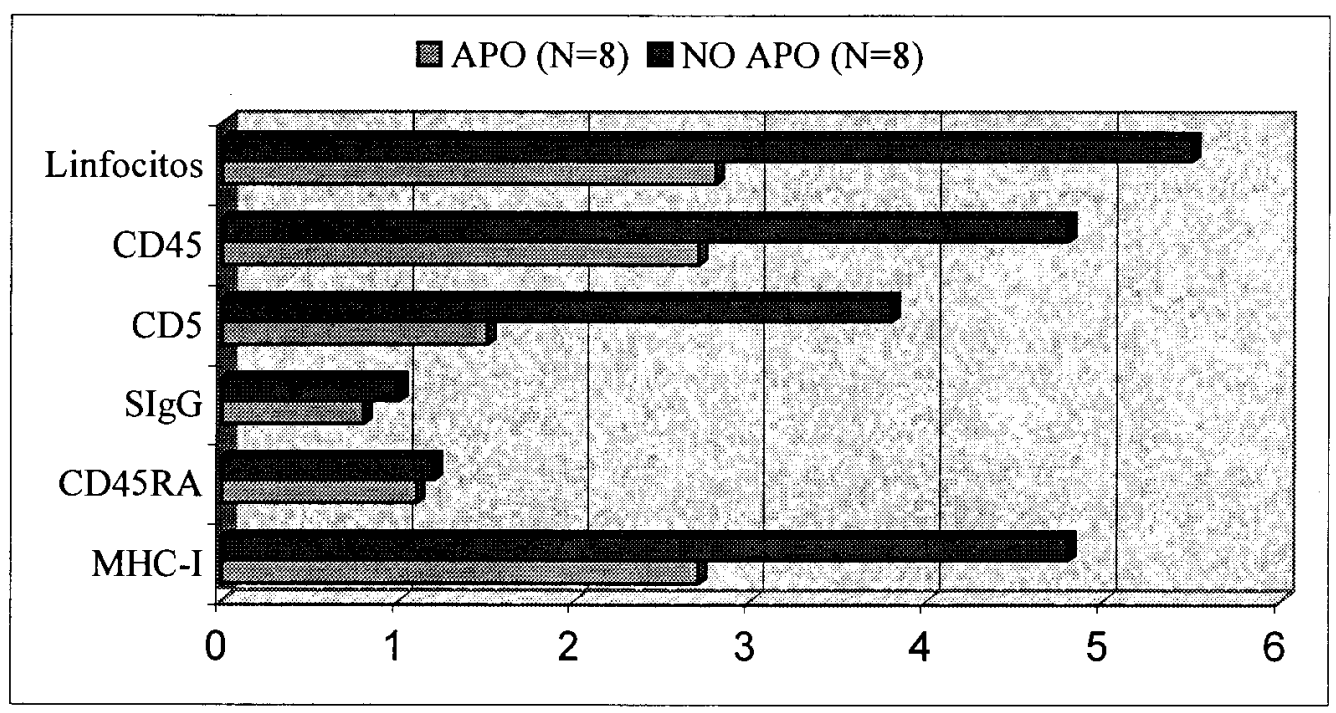

Figura la. Números absolutos de linfocitos periféricos $\left(10^{3} \mathrm{ml}^{-1}\right.$ de sangre $)$ en animales clínicamente enfermos con APO y controles. 


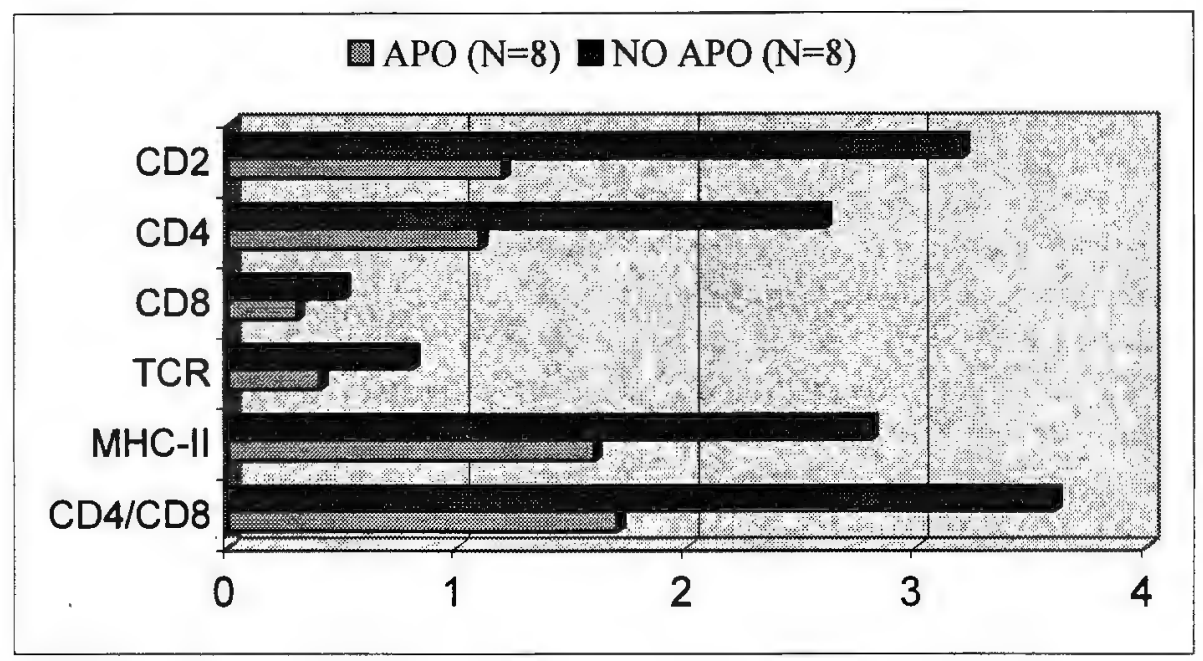

Figura lb. Números absolutos de linfocitos periféricos $\left(10^{3} \mathrm{ml}^{-1}\right.$ de sangre $)$ en animales clínicamente enfermos con APO y controles.

alcanzan hasta $35 \%$ de células sIgG + y $40 \%$ CD45RA+ estuvo asociado con otras anormalidades funcionales de células B. Los niveles de IgG estuvieron elevados en animales afectados con APO comparado con animales no afectados $\left(34.8 \pm 11.9 \mathrm{~g} \mathrm{l}^{-1}\right.$ vs $19.8 \pm 5.8 \mathrm{~g} \mathrm{l}^{-1}$ $\mathrm{p}<0.001$ ) y la respuesta a la estimulación de LPS en muestras sanguíneas de animales afectados con APO fue aproximadamente cuatro veces más elevado comparado con dos muestras de no afectados $(8.07 \pm 1.55$ vs $2.4 \pm 0.42)$. La reducción significativa en números y proporciones de los linfocitos $\mathrm{T}$ auxiliares produjo una alteración en la relación periférica CD4/CD8 variando desde una proporción de $3.9 \pm 3$ observada en animales no afectados por APO hasta $1.4 \pm 0.6$ en los animales afectados por APO $(\mathrm{p}<0.05)$ (Figura 2).

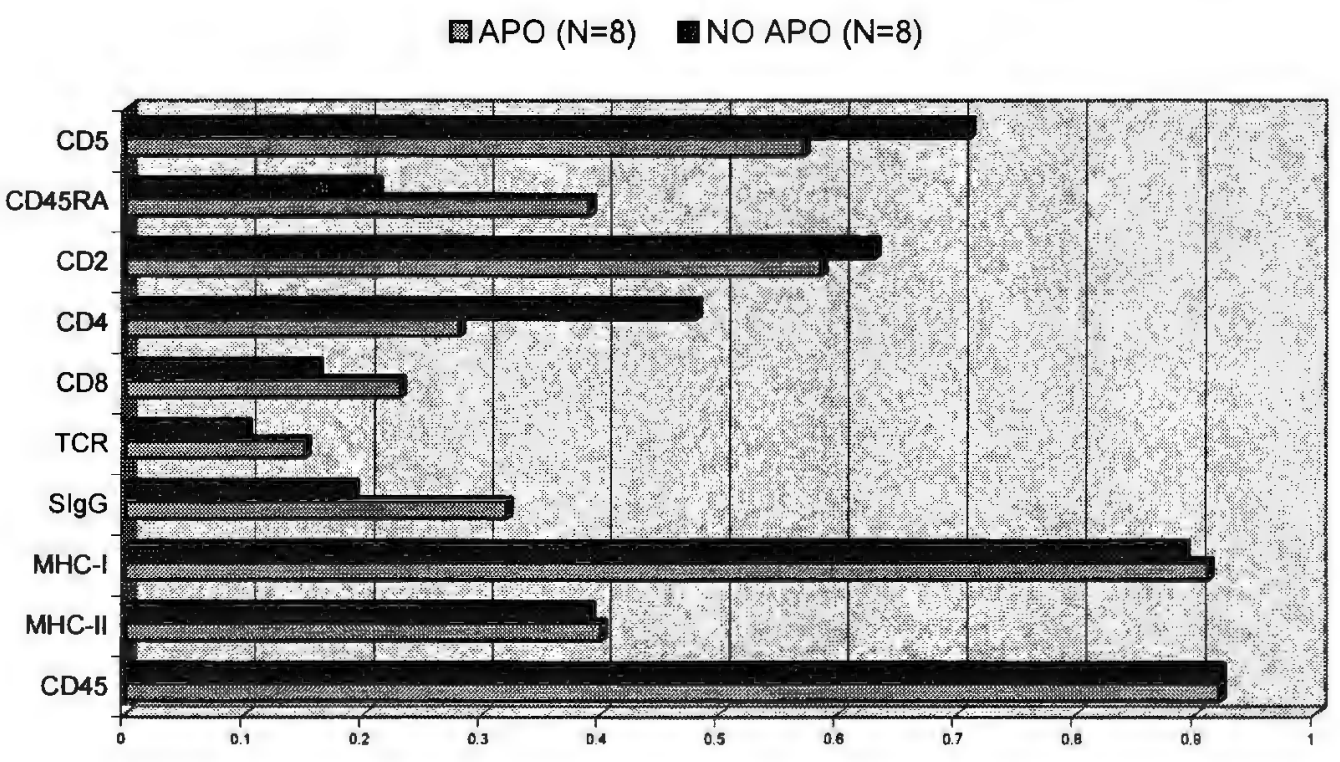

Figura 2. Proporciones de subpoblación linfoide en linfocitos periféricos de animales clínicamente enfermos con APO y controles. 
Similares alteraciones fueron observadas en los corderos experimentales severamente afectados en forma experimental $(n=5)$. En estos animales, se observó una significativa reducción de leucocitos circulantes $\left(6.92 \pm 2.32 \times 10^{3}\right.$ células $\mathrm{ml}^{-1} \mathrm{de}$ sangre) comparado con los animales controles $(n=7)\left(10.56 \pm 2.03 \times 10^{3}\right.$ células $\mathrm{ml}^{-1} \mathrm{de}$ sangre) (Cuadro 3). Esta reducción no fue encontrada en los animales clasificados con tener lesiones leve a moderado de APO $(n=4)$. En estos cuatro animales, muy por el contrario, evidenciaron un ligero aumento leucocitario $\left(12.60 \pm 2.32 \times 10^{3}\right.$ células $\mathrm{ml}^{-1} \mathrm{de}$ sangre) (Cuadro 3). El uso de los paneles de AcMo determinó que la reducción linfocitaria en los cinco corderos severamente afectados alteró fundamentalmente las células CD5t, $\mathrm{CD} 2+, \mathrm{CD} 4+\mathrm{y}$ células que expresan antígenos MHC-II. La disminución de células CD4+en los corderos severamente afectados también alteró la relación de CD4/CD8. En estos animales se observaron una relación de $0.85 \mathrm{com}$ parado con 1.94 determinado en los controles y 1.79 mostrado por corderos con lesiones de APO considerados como leve (Cuadro 4).

Cuadro 3. Leucocitos sanguíneos periféricos de corderos experimentalmente inducidos con APO ( $x 10$ células $x$ uL de sangre).

\begin{tabular}{lccc}
\hline & Controles $(\mathrm{n}=7)$ & APO leve $(\mathrm{n}=4)$ & APO severo $(\mathrm{n}=5)$ \\
\hline Número total de células blancas & $10.56 \pm 2.03$ & $12.60 \pm 2.12$ & $6.92 \pm 2.32$ \\
Linfocitos & $8.91 \pm 1.86$ & $9.93 \pm 1.96$ & $4.72 \pm 1.35$ \\
Neutrófilos & $1.28 \pm 0.56$ & $2.30 \pm 0.62$ & $1.97 \pm 1.47$ \\
Monocitos & $0.23 \pm 0.20$ & $0.29 \pm 0.13$ & $0.14 \pm 0.15$ \\
Eosinófilos & $0.12 \pm 0.22$ & $0.09 \pm 0.11$ & $0.02 \pm 0.04$ \\
\hline
\end{tabular}

Cuadro 4. Corderos experimentalmente inducidos con APO: Subpoblaciones de linfocitos periféricos expresados $\times 10^{3}$ células por $\mu \mathrm{L}$ de sangre.

\begin{tabular}{llll}
\hline Célula & Controles $(\mathrm{n}=7)$ & APO leve $(\mathrm{n}=4)$ & APO severo $(\mathrm{n}=5)$ \\
\hline Linfocitos & $8.87 \pm 1.87$ & $9.93 \pm 1.96$ & $4.72 \pm 1.35^{*}$ \\
CD5 & $5.27 \pm 1.52$ & $5.57 \pm 1.03$ & $2.58 \pm 0.84^{*}$ \\
CD45R & $3.08 \pm 1.19$ & $4.29 \pm 1.46$ & $2.27 \pm .0 .9$ \\
CD2 & $3.33 \pm 0.94$ & $2.93 \pm 0.46$ & $1.59 \pm 0.34^{*}$ \\
CD4 & $2.0 \pm 0.47$ & $1.92 \pm 0.25$ & $0.68 \pm 0.06^{*}$ \\
CD8 & $1.03 \pm 0.26$ & $1.07 \pm 0.38$ & $0.8 \pm 0.4$ \\
$\gamma \delta$ TCR & $2.46 \pm 1.04$ & $2.96 \pm 1.43$ & $1.41 \pm 0.62$ \\
slgG & $2.42 \pm 1.27$ & $3.98 \pm 1.63$ & $1.73 \pm 0.95$ \\
MHC-I & $8.14 \pm 1.9$ & $8.79 \pm 1.88$ & $4.41 \pm 1.55$ \\
MHC-II & $3.32 \pm 0.86$ & $4.9 \pm 2.11$ & $2.11 \pm 0.71^{*}$ \\
CD4/CD8 & 1.94 & 1.79 & 0.85 \\
\hline
\end{tabular}

* Estadísticamente significativo $(\mathrm{p} \leq 0.5)$

El análisis de las células recuperadas por lavados pulmonares de animales afectados por APO mostraron evidentes alteraciones en recuentos totales de células y en ciertas proporciones linfocitarias. Los animales afectados con APO tenían 24 veces aumentado el número total de células frente a los animales no afectados por APO. En este incremento, los neutrófilos estuvieron aumentados en 185 veces, los macrófagos 
alveolares en 24 veces y los linfocitos en 11 veces (Cuadro 5). El análisis diferencial muestra que ambos tipos de animales (APO y no APO) mantenían proporciones similares en macrófagos alveolares. Pero, a los pulmones de los animales no afectados por APO ingresan o mantienen más linfocitos (18.3\%), más eosinófilos (5\%), y menos neutrófilos $(2.7 \%)$ que las encontradas en las muestras de APO que contenían un $8 \%$ (linfocitos), $0.2 \%$ (neutrófilos) y 27\% de neutrófilos (Cuadro 5). Los lavados pulmonares procedentes de los corderos severamente infectados contenían 11 veces más leucocitos y 8 veces más macrófagos alveolares y linfocitos que los animales control (Cuadro 6).

Cuadro 5. Células totales y diferenciales en muestras de lavados pulmonares $\left(10^{5}\right.$ células $\left.\mathrm{ml}^{-1}\right)$ en borregas presentando severas disfunciones respiratorias.

\begin{tabular}{|c|c|c|c|c|c|}
\hline Grupo & Total células & $\begin{array}{c}\text { Macrófago } \\
\text { Alveolar }\end{array}$ & Linfocitos & PMNs & EOs \\
\hline APO & $53.2 \pm 28.3$ & $37.6 \pm 19.7$ & $4.3 \pm 2.4$ & $11.1 \pm 8.5$ & $0.09 \pm 0.1$ \\
\hline $\mathrm{n}=10$ & & $70.7 \%$ & $8 \%$ & $21 \%$ & $0.2 \%$ \\
\hline NO-APO & $2.2 \pm 1.4$ & $1.63 \pm 0.98$ & $0.4 \pm 0.37$ & $0.06 \pm .04$ & $0.1 \pm 0.1$ \\
\hline$n=6$ & & $74 \%$ & $18.2 \%$ & $2.7 \%$ & $5 \%$ \\
\hline Relación & 24 & 24 & 10.8 & 185 & 0.9 \\
\hline
\end{tabular}

Cuadro 6. Recuento totales y diferenciales en muestras de lavados pulmonares en corderos controles y experimentalmente infectados.

\begin{tabular}{lccc}
\hline & Controles $(\mathrm{n}=7)$ & APO leves $(\mathrm{n}=4)$ & APO severos $(\mathrm{n}=5)$ \\
\hline Volumen recuperado fluido lavado & & & \\
pulmonar $(\mathrm{ml})$ & $280 \pm 25$ & $262.5 \pm 25$ & $231 \pm 21.3$ \\
Total leucocitos $\left(\times 10^{4}\right)$ & $42.9 \pm 33.9$ & $227.8 \pm 198.2$ & $461 \pm 622.3$ \\
M $\phi$ alveolar $\left(\mathrm{x} \mathrm{10} 0^{4}\right)$ & $36.8 \pm 27.5$ & $178 \pm 136.5$ & $314 \pm 380.9$ \\
Linfocitos pulmonares $\left(\mathrm{x} 10^{4}\right)$ & $4.87 \pm 5.2$ & $22.9 \pm 12.9$ & $38.4 \pm 44.4$ \\
\hline
\end{tabular}

El análisis de citometría de flujo en muestras de lavados pulmonares evidenciaron un ingreso importante de leucocitos hacia los pulmones afectados con APO, pero mostraron alteraciones en la proporción de las diferentes subpoblaciones linfocíticas. A pesar del ingreso significativo de células leucocitarias comparado con animales no afectados con APO, se logra observar una proporción disminuida, principalmente, en las células identifi- cadas con $\mathrm{CD} 5+(\mathrm{p}=0.6), \mathrm{CD} 4+(\mathrm{p}=0.03) \mathrm{y}$ células que expresan antígenos MHC-I $(\mathrm{p}=0.12)$. Se observó además un aumento en la proporción de células marcadas con CD8+ $(\mathrm{p}=0.06)$ pero $\sin$ variaciones significativas en las proporciones de $\mathrm{CD} 2+$, $\delta \gamma \mathrm{TCR}+$, sIgG+ y células que expresan antígenos MHC-II (Figura 3). Como consecuencia de estas alteraciones, las proporciones de linfocitos pulmonares $\mathrm{T}(\mathrm{CD} 5+)$ : $\mathrm{B}(\operatorname{sIgG}+)$ variaron 


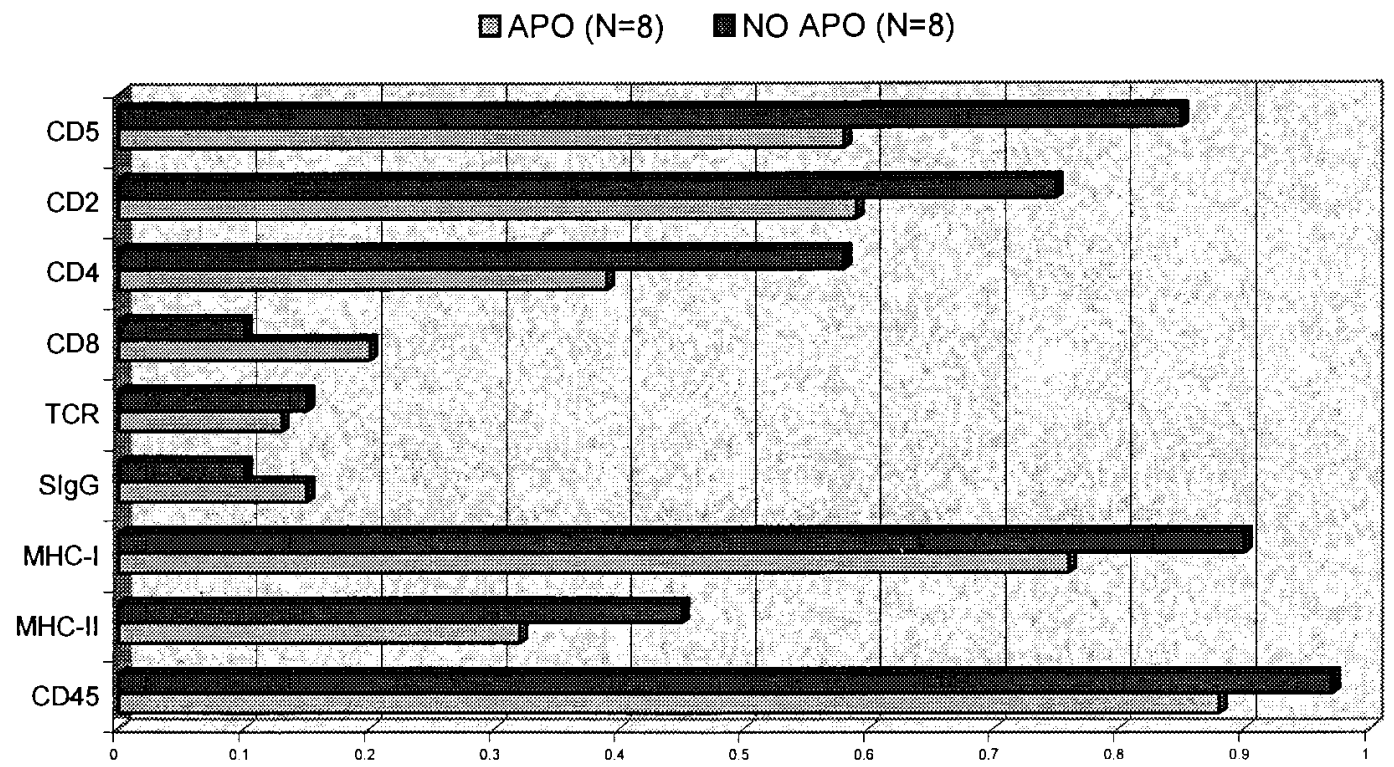

Figura 3. Proporciones de subpoblación linfoide en linfocitos pulmonares de animales clínicamente enfermos con APO y controles.

desde $84 \%: 12 \%$ (no APO) a $61 \%: 16 \%$ en pulmones afectados con APO. Similarmente, las proporciones de células CD4 : CD8 cambiaron de $58 \%: 14 \%$, observadas en animales no afectados, a $41 \%: 21 \%$ respectivamente en animales afectados. Se observó además que ambos grupos de animales afectados y no afectados con APO mostraron número elevado de linfocitos $\delta \gamma \mathrm{TCR}+$.
Estas alteraciones también fueron detectadas en los corderos infectados experimentalmente. A pesar de ingresar mucho más células leucocitarias a los pulmones afectados (Cuadro 7) existen evidencias de proporciones disminuidas de células B (CD45RA+ y sIgG+) e incremento en células que expresan MHC-II en los corderos severamente afectados (Cuadro 8).

Cuadro 7. Corderos experimentalmente inducidos con APO: Subpoblaciones de linfocitos pulmonares $\times 10^{4}$ células por $\mathrm{ml}$ de lavado pulmonar.

\begin{tabular}{lccc}
\hline Célula & Controles $(\mathrm{n}=7)$ & APO leve $(\mathrm{n}=4)$ & APO severo $(\mathrm{n}=5)$ \\
\hline Linfocitos & $4.9 \pm 5.2$ & $23 \pm 13^{*}$ & $38.4 \pm 44.4^{*}$ \\
CD5 & $4.0 \pm 4.7$ & $21.2 \pm 11.6^{*}$ & $33 \pm 39.3^{*}$ \\
CD45R & $0.8 \pm 1.1$ & $1.1 \pm 0.1$ & $3.4 \pm .4$ \\
CD2 & $3.3 \pm 4$ & $15.9 \pm 7.4^{*}$ & $24.6 \pm 27.4^{*}$ \\
CD4 & $2.5 \pm 3.3$ & $11.4 \pm 5^{*}$ & $18 \pm 19.6$ \\
CD8 & $0-9 \pm 1$ & $5.9 \pm 2.9^{* *}$ & $7.4 \pm 7.6^{*}$ \\
$\gamma \delta$ TCR & $0.6 \pm 0.5$ & $2.6 \pm 0.7^{* *}$ & $3.9 \pm 3.6^{*}$ \\
sIgG & $0.7 \pm 1.1$ & $0.7 \pm 0.3$ & $2.6 \pm 2.8$ \\
MHC-I & $4.9 \pm 5.8$ & $22.7 \pm 12.6$ & $37.2 \pm 42.8$ \\
MHC-II & $1.7 \pm 1.9$ & $4.9 \pm 5.8$ & $13.7 \pm 13^{*}$ \\
CD4/CD8 & 2.6 & 2.2 & 2.2 \\
\hline
\end{tabular}

* Estadísticamente significativo $(\mathrm{p} \leq 0.5) \mathrm{y}^{* *}(\mathrm{p} \leq 0.0 \mathrm{l})$ 
Cuadro 8. Corderos experimentalmente inducidos con APO: proporciones de subpoblaciones de linfocitos pulmonares.

\begin{tabular}{|c|c|c|c|}
\hline Célula & Controles $(n=7)$ & APO leve $(n=4)$ & APO severo $(n=5)$ \\
\hline CD5 & $0.82 \pm 0.14$ & $0.93 \pm 0.03$ & $0.84 \pm 0.07$ \\
\hline CD45R & $0.15 \pm 0.12$ & $0.06 \pm 0.03$ & $0.09 \pm 0.03$ \\
\hline $\mathrm{CD} 2$ & $0.68 \pm 0.15$ & $0.62 \pm 0.2$ & $0.64 \pm 0.10$ \\
\hline CD4 & $0.49 \pm 0.11$ & $0.45 \pm 0.2$ & $0.46 \pm 0.15$ \\
\hline CD8 & $0.22 \pm 0.09$ & $0.24 \pm 0.14$ & $0.24 \pm 0.07$ \\
\hline$\gamma \delta \mathrm{TCR}$ & $0.11 \pm 0.05$ & $0.12 \pm 0.06$ & $0.13 \pm 0.03$ \\
\hline $\operatorname{sIgG}$ & $0.12 \pm 0.14$ & $0.04 \pm 0.03$ & $0.08 \pm 0.02$ \\
\hline MHC-I & $0.94 \pm 0.11$ & $0.99 \pm 0.01$ & $0.96 \pm 0.04$ \\
\hline MHC-II & $0.30 \pm 0.11$ & $0.20 \pm 0.13$ & $0.45 \pm 0.12$ \\
\hline
\end{tabular}

Los pesos de los pulmones de los corderos severamente afectados se encontraban incrementados en más de dos veces que el de los controles (Cuadro 9). Sin embargo, el peso de órganos linfoides (nódulos linfáticos regionales, timo cervical y torácico) se encontraban marcadamente reducidos (Cuadro 9). Los exámenes histopatológico de estos tejidos mostraron evidencias de severa reducción linfocitaria principalmente en el timo. El timo mostró una marcada despoblación linfoide principalmente en la corteza tímica que produjo una dramática reducción en la relación corte$\mathrm{za} /$ médula tímica. La médula mostraba un número elevado y formaciones desproporcionadas y/o aberrantes de corpúsculos de Hassal y/o presencia de microquistes (Figura 4a). En forma inconsistente se logró ver la presencia de células en proceso de degeneración. La corteza tímica, además, mostró evidencias de tejido graso que se infiltraban tejido parenquimal por debajo de la corteza tímica (Figura 4a). Al encontrarse estas evidencias de despoblación linfoide en el timo se procedió a analizar algunos tejidos esplénicos $(n=2)$ en aquellos animales que evidenciaron una severa despoblación linfoide en nódulos esplénicos y manto periarteriolar (Figuras 5a). En ambos tipos de tejidos no se lograron observar evidencias directas de linfocitolisis.

Cuadro 9. Corderos experimentalmente inducidos con APO. Pesos de pulmones y órganos linfoides expresados en gramos.

\begin{tabular}{lccc}
\hline & Controles $(\mathrm{n}=7)$ & APO leve $(\mathrm{n}=4)$ & APO severo $(\mathrm{n}=5)$ \\
\hline Pulmones & $354 \pm 99$ & $590 \pm 138$ & $884 \pm 181$ \\
Nódulo linfático bronquial & $6.0 \pm 4.2$ & $5.0 \pm 2.8$ & $3.0 \pm 1.4$ \\
Nódulo linfático mediastínico & $8.4 \pm 2.7$ & $7.4 \pm 4.6$ & $5.8 \pm 3.3$ \\
Timo cervical & $50.1 \pm 28.8$ & $48.6 \pm 41.3$ & $30 \pm 16.2$ \\
Timo torácico & $29.4 \pm 7.8$ & $27.7 \pm 15.9$ & $21.2 \pm 8.9$ \\
\hline
\end{tabular}

\section{Disention}

El uso de anticuerpos monoclonales con capacidad de identificar subpoblaciones linfoides en ovinos y determinaciones hematológicas realizadas en animales naturalmente enfermos de APO y en corderos neonatos experimentalmente infectados indican la presencia de alteraciones en células linfoides en sangre circulante así 
como en células que ingresan al tejido pulmonar. Los animales clínicamente enfermos exhibieron una clara linfopenia, caracterizada por una disminución significativa no solamente en números totales sino también en proporciones de subpoblaciones celulares, fundamentalmente disminución de células identificadas con los marcadores de CD5+y linfocitos CD4+ dependiente de MHC-I. Estos animales mostraron, además, un incremento en las proporciones de linfocitos CD8+ y células $\mathrm{B}(\mathrm{CD} 45 \mathrm{RA}+$, sIgG +$)$. Hasta donde se tenga conocimiento, esta es la primera descripción sobre identificación de $\mathrm{CD} 4+$ linfocitopenia circulante en animales que padecen de APO. La severa reducción de linfocitos $\mathrm{CD} 4+$ circulante en estos animales ocasiona un desbalance negativo en la relación de CD4/CD8 de manera similar a lo descrito en enfermedades inmunosupresivas ocasionadas por infecciones retrovirales en humanos y gatos (Hoffmann-Fezer et al., 1992).

Los cambios asociados con elevada proporción de células con marcadores de linfocitos B explica el significativo aumento de gammaglobulinemia en los animales clínicamente enfermos con la enfermedad y tiende a corroborar la hipergammaglobulinemia descrita con anterioridad (Hod et al., 1972). El elevado número de células $\mathrm{B}(\mathrm{CD} 45 \mathrm{RA}+)$ encontrados en animales enfermos naturalmente con APO fueron igualmente confirmados por los altos niveles de activación linfocítica estimulados in vitro con LPS (mitógeno específico de células B) realizado en 3 animales afectados. Esta aparente sobrestimulación de las células B observada en el estudio contradice lo reportado sobre la incapacidad del retrovirus productor de APO de inducir anticuerpos específicos contra el agente retroviral (Herring et al., 1983) pero sugiere que esta respuesta tal vez sea completamente inespecífica. Debe anotarse que similares disfunciones tales como hipergammaglobulinemia e incremento en la activación de células $\mathrm{B}$ se logran observar pacientes infectados por el virus HIV y atribuidas como consecuencia de una respuesta predominantemente mediada por la subpoblación $\mathrm{Th}_{2}$ de las células $\mathrm{CD} 4+$ (Clerici y Sherer, 1993). Las anormalidades cuali y cuantitativas de las células $B$ tienden a asociarse con cambios progresivos de la enfermedad en pacientes afectados por el SIDA (Zouali, 1995). La aparente desregulación de las células $B$ observadas claramente en animales naturalmente enfermos por APO, tiende a sugerir que este tipo de disfunción estaría asociado con estadios terminales de la enfermedad. Pues los corderos infectados con inóculos experimentales no muestran un aumento significativo en la población de células $\mathrm{B}$ y muy por el contrario los corderos que terminaron lesiones ligeras de APO tenían disminuídas las células con marcadores SIgG+ (4\%) y los severamente afectados $(8 \%)$, comparados con el $12 \%$ observado en animales controles (Cuadro 8).

Los resultados de los análisis sobre el total de células recuperadas en los pulmones naturalmente afectados difieren de lo previamente reportado para animales aparentemente normales (Burrells y Sutherland, 1993) y demuestran que existe un tráfico celular muy intenso hacia el tejido pulmonar neoplásico. Muy poco se sabe sobre el origen de células inmuno-inflamatorias que controlan el tráfico celular hacia los pulmones infectados. Se desconoce también cuales son los orígenes y/o estímulos específicos responsables para el reclutamiento celular. El flujo celular pulmonar tal vez provenga y sea consecuencia de una redistribución celular periférica, pero igualmente puede ser consecuencia de una proliferación in situ en respuesta a ciertas necesidades patológicas (Semenzato, 1991). La linfocitopenia periférica observada en ovinos afectados con APO asociada con el aumento de linfocitos observados en muestras obtenidas de lavados pulmonares tiende a apoyar al modelo de redistribución celular. Sin embargo, a pesar del aumento de linfocitos en los pulmones afectados por APO, se observa igualmente una selectiva reducción de ciertas subpoblaciones tales como de células $\mathrm{CD} 5+\mathrm{y}$ fundamentalmente linfocitos $\mathrm{CD} 4+$. En estos animales, además 
se logra observar un incremento en las proporciones de $\mathrm{CD} 8+\mathrm{y}$ células $\mathrm{B}(\mathrm{sIgG}+\mathrm{y}$ CD45RA+).

$\mathrm{La} \mathrm{CD} 4+$ linfocitopenia son al parecer únicas en animales afectados por el retrovirus productor del APO. Ovinos naturalmente enfermos con la forma respiratoria (Maedi) $y$ producto de una infección lentiviral no muestran alteraciones en la subpoblaciones de $\mathrm{CD} 4+$ periférico y muy por el contrario las células CD4+ y CD8+ se encuentran aumentadas al compararlas con los animales no afectados por el lentivirus (Cordier et al., 1992). La evidente predilección retroviral APO por el tejido linfoide tiende a sustentarse en los cambios macro y microscópicos observado en tejido linfoides de corderos experimentalmente infectados con APO. En estos corderos, se observaron reducciones de pesos de los tejidos linfoides pero fundamentalmente en tímos cervicales y torácicos. En todos los corderos inoculados y que desarrollaron la enfermedad se comprobaron tendencia en la reducción de peso tímico pero los cambios fueron mucho más dramáticos en aquellos corderos severamente afectados (Cuadro 9).

La severa depleción linfoide observada en el timo de estos corderos, tiende a sugerir que deficiencia de células CD4+ periférica y pulmonar sea consecuencia de la afinidad viral por linfocitos tímicos. Por otro lado, la depleción linfoide tímica también explicaría la reducción de peso de los nódulos linfáticos pulmonares y sobre todo la despoblación linfoide esplénica observada en $\operatorname{los} 2 / 2$ corderos estudiados (Figuras 4 a y $5 a$ ). Desgra-ciadamente, al término de la ejecución del presente trabajo no se disponía de técnicas moleculares para identificar al agente retroviral en tejidos lindoides. Sin embargo, el uso de la técnica de transcriptasa reversareacción en cadena de la polimerasa (RTPCR) ha comprobado, recientemente, la presencia del retrovirus causante del APO en muestras de médula ósea, nódulo linfático y timo (Palmarini et al., 1996). Consecuentemente, es altamente tentador, sugerir que la linfocitopenia de $\mathrm{CD} 4+$ principalmente la periférica es consecuencia de una citotoxicidad viral o producto de una eliminación clonal de células $\mathrm{T}$, particularmente de células CD4t.

El incremento de macrófagos alveolares observados en muestras de lavados pulmonares de animales enfermos con APO fue hasta cierto punto esperado. Estas células infiltran extensivamente los espacios alveolares alrededor de los focos tumorales (Cuba Caparó et al., 1961; Rosadio et al., 1988a; Sharp y Angus, 1990a) y están presentes en elevadas proporciones en muestras en tejidos tumorales desagregados y en muestras producto de lavados pulmonares (Jassim et al., 1987; Myer et al., 1987). La presencia de macrófagos en tejidos afectados por el retrovirus es muy probable se deba a la excesiva cantidad de material surfactante producido por los neumonocitos transformados. Sin embargo, las acumulaciones masivas de macrófagos alveolares podrían muy bien ser fuente de algún factor, aún desconocido, con capacidad de potenciar, exacerbar el proceso tumoral y/o participar en el proceso tumorogénico. Estas posibles habilidades se sustentan en las observaciones de ciertos efectos interactivos reportados ocurrir entre macrófagos y tumores no pulmonares (Buick et al., 1980; Nelson et al., 1985) y a la cierta habilidad de inducir síntesis de ADN en neumonocitos de tipo II en ratas (Leslie $e t$ al., 1985).

La reducción significativa en las proporciones de células CD5+ y CD4t en linfocitos pulmonares en muestras de lavados pulmonares de animales afectados por APO tienden a sugerir que los linfocitos en el lecho pulmonar están en constante activación (pérdida de antígeno de membrana CD5) que terminarían selectivamente por eliminar subpoblaciones de CD4+ (Luján et al., 1993). La relación de linfocitos $\mathrm{T} / \mathrm{B}$ y CD4/CD8 que se encontraron en pulmones de animales no afectados con APO son similares a lo encontrado en pulmones normales (Burrello y Sutherland, 1993), pero son distintas a lo observado en animales afectados con APO. Las 
proporciones de linfocitos T $\delta \gamma$ encontrados en ambos grupos de animales (APO y no $\mathrm{APO}$ ) son más elevadas de lo previamente reportado (Burrells y Sutherland, 1993) y tal vez reflejen respuesta a proteínas o shock proteíco producido por células estresadas (Hein \& Mackay 1991b). Estos resultados refuerzan la idea que en el tejido neoplásico se liberan constantemente factores quimiotácticos de fuerte atracción a células linfoides que terminarían por producir las alteraciones observadas en los pulmones de animales naturalmente enfermos con APO.

La elevada proporción de células CD8+ en muestras de lavados pulmonares tal vez sea un reflejo de la respuesta del hospedero para suprimir o eliminar a las células epiteliales transformadas por el retrovirus. Esta aseveración se sustenta por hallazgos similares que han sido reportados en muestras de lavados pulmonares en pacientes afectados con adenocarcinoma pulmonar humano (Ginns et al., 1982; Wesselius et al., 1985), tumores pulmonares murinos (Scott y Kauffmann, 1991) y en linfomas ovinos producto de infección por el virus de la leucemia bovina. Estas observaciones conjuntamente con nuestros resultados, tienden a sugerir un rol, aún por comprobarse, de las células CD8+ en el intento de eliminar a las células transformadas. Por otro lado, los linfocitos CD8+ son esenciales en lisar células infectadas por virus y consecuentemente son células responsables, por ejemplo, de la recuperación de ovinos infectados por un virus neumotrópico como el virus sincitial bovino (Sharma et al., 1990; Sharma y Woldehiwet, 1991). Paradójicamente, la elevada concentración de células CD8 + tal vez sea causante de la elevada concentración viral en las secreciones nasales observada en los animales afectados, de manera similar a la posible implicación de las células CD8+ en la excreción de lentivirus en leche y secreción pulmonar en animales infectados por el virus Maedi/Visna (Ouzrout et al., 1991).

El presente estudio demuestra que ovinos naturalmente enfermos y experimentalmente inducidos con APO padecen de disfunciones inmunes caracterizadas por linfocitopenia CD4+ circulante, desregulacio-nes de células $B$ (proporciones aumentadas periféricas y pulmonares de células sIgG+; hipergammaglobulinemia y respuesta aumentada a mitógenos para células $B$ en animales naturalmente enfermos) y una elevada proporción de células CD8+y linfocitos $\mathrm{T} \delta \gamma$ pulmonares en animales clínicamente enfermos. Las alteraciones de subpoblaciones linfoides se sustentan con evidencias de una acelerada involución tímica en corderos experimentalmente infectados tales como: reducción de peso tímico, hipoplasia linfocítica cortical e incremento en números y formas alteradas de corpúsculos de Hassal.

Todas estas alteraciones linfoides sugieren que el retrovirus productor del APO replicaría en tejido linfoide capaz de desencadenar cuadros de inmunodeficiencias que explicaría la aparente susceptibilidad de estos animales a superinfecciones pulmonares a diversos agentes patógenos y principalmente a pasteurelosis neumónica. La responsabilidad retroviral de la linfocitopenia CD4+ tendrá que ser comprobada. Sin embargo, la reciente demostración de la predilección del retrovirus del APO por tejido linfoide (Palmarini et al., 1996) demuestra potencial capacidad inmunosupresora de este agente de una manera muy similar a otras infecciones virales inmunosupresoras hasta ahora descritas, tales como el virus productor del SIDA (HIV), inmunodeficiencia felina (FeLV) y pestivirus ovino. Estos resultados fundamentalmente evidencian una gran semejanza a la biología del retrovirus tipo B murino en la habilidad de utilizar tejido linfoide para ingresar, proliferar y finalmente arribar a tejido epitelial para desencadenar carcinoma mamario.

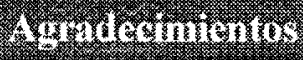

Los autores agradecen muy especialmente al Sr. Andrew Sanderson, Departamento 
de Zoología y David Hitchcock, Departamento de Estadística de la Universidad de Edinburgo por su asistencia en la utilización del FASC y los análisis estadísticos respectivamente. Igualmente, agradecen a Charles Burrells y David Dean, Moredun Institute por proveernos del panel de anticuerpos

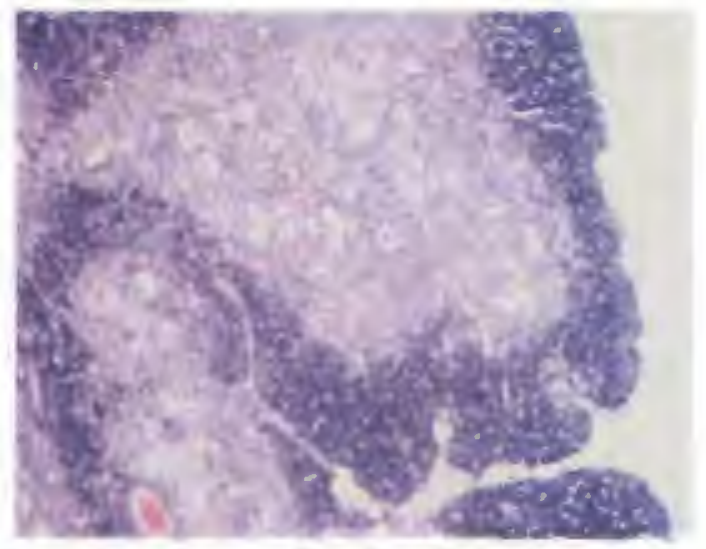

Figura 4a. Timo de un cordero severamente infectado (6 semanas post inoculación). Nótese despoblación linfoide y presencia de infiltración grasa en la corteza y microquístes en la médula.

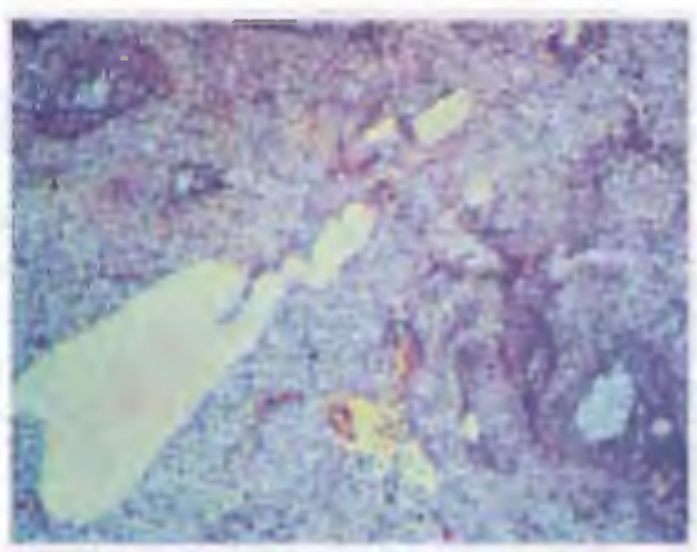

Figura 5a. Bazo de un cordero severamente infectado (10 semanas post inoculación). Nótese severa despoblación linfoide en nódulos esplénicos y manto periarteriolar y presencia de microquiste en pulpa blanca. monoclonales. A los Srs Collin Malloy, Patricia Dewar y Christina Wilson por su apoyo en la ejecución del trabajo. El autor Raúl Rosadio fue becario del Directorado general para la ciencia, investigación y desarrollo de la Comisión de la Comunidad Europea.

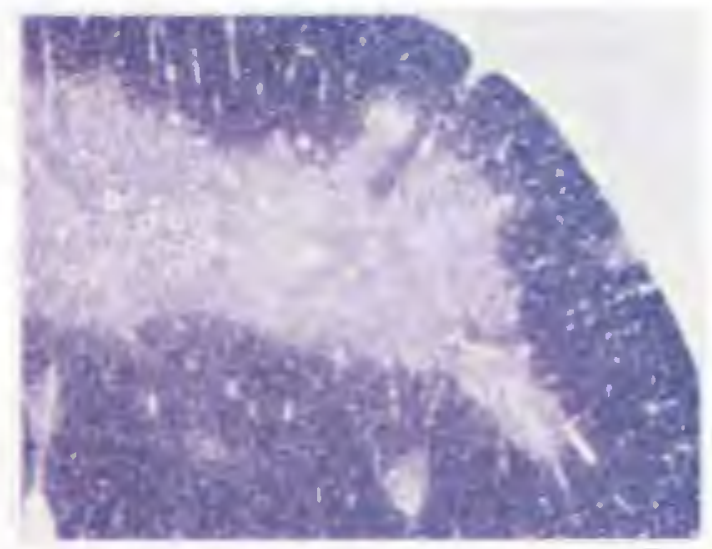

Figura 4b. Timo aparentemente normal de cordero control (6 semanas de edad). Nótese celularidad normal en la corteza y buena relación corteza/médula

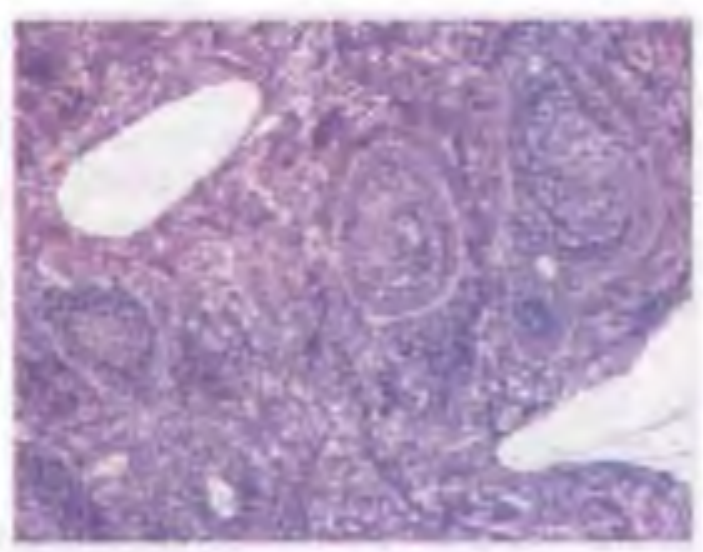

Figura 5b. Bazo aparentemente normal de cordero control (6 semanas de edad). 
biteritina Cinds

1. Buick, R.N.; S.N. Fry y S.E. Salmon. 1980. Effect of host-cell interactions of colonogenic carcinoma cells in human malignant effusions. Brit. J. Cancer. 41:695-704.

2. Burrells, C. 1985. Cellular and humoral elements of the lower respiratory tract of the sheep. Immunological examination of cells and fluid obtained by bronchoalveolar lavage of normal sheep. Vet. Immunol. Immunopath. 10:225-243.

3. Burrells, C.; P.F. Nettleton; H.W. Reid; H.R.P. Miller; J. Hopkins; I. McConnell; M.D. Gorrell y M.R. Brandon. 1989. Lymphocyte subpopulations in the blood of sheep persistently infected with border disease virus. Clin. Exp. Immunol. 76:446-451.

4. Burrells, C. y A.D. Sutherland. 1993. Phenotypic analysis of lymphocytes obtained by bronchoalveolar lavage of normal sheep. Vet Immunol Immunopathol 37: 101-107

5. Clerici, M. y G.M. Shearer. 1993. A $T_{H} 1$ à $T_{H} 2$ switch is a critical step in the etiology of HIV infection. Immunology Today, 14:107-111.

6. Cuba, A. 1945. La poliadenomatosis pulmonar del carnero. Boletín de la Escuela de Ciencias Veterinarias 1:27-60.

7. Cuba Caparó, A.; E. De la Vega y M. Copaira. 1961. Pulmonary adenomatosis of sheep; a metastasizing bronchiolar tumor. Am. J. Vet. Res., 22:673-682.

8. De Martini, J.C.; R.H. Rosadio; J.M. Sharp; H.I. Russell y M.D. Lairmore. 1987. Experimental conduction of type $D$ retrovirus- associated pulmonary carcinoma and lentivirus-associated lymphoid interstitial pneumonia in lambs. J. Nat. Cancer Inst 79:167-177.

9. De Martini, J.C.; R.H. Rosadio y M.D. Lairmore. 1988. The etiology and pathogenesis of ovine pulmonary carcinoma (sheep pulmonary adenomatosis) Vet Microbiology 17:219-236.

10. Fajac, I.; A. Tazi; A.J. Hause; F. Bouchonnet; M. Riquet; J.P. Battesti $y$ P. Soler. 1992. Lymphocytes infiltrating normal and lung carcinomas rarely express gamma delta $T$ cell antigen receptors. Clin. Exp. Immunol. 87:127-131.

II. Ginns, L.C.; P..D. Goldenheim; L.G Miller; R.C. Burton; L. Gillick; R.B. Colvin; $G$ Goldstein; P.C. Kung; $C$. Hurwitz y H. Kazemi. 1982. Tlymphocyte subsets in smoking and lung cancer. Analysis by monoclonal antibodies and flow cytometry. Am. Rev. Respir. Dis. 126:265-269.

12. Hein, W.R. y C.R. Mackay. 1991a. Prominent of gdT cells in the ruminant immune system. Immunol. Today 12:30-34.

13. Hein, W.R. y C.R. Mackay. 1991b. Other surface antigens identified on sheep leukocytes. Vet. Immunol. Immunopath. 27:115-118

14. Herring A.J.; J.M. Sharp; F.M. Scott y K.W. Angus. 1983. Furher evidence for a retrovirus as the etiological agent of sheep pulmonary adenomatosis (Jaagsiekte). Vet Microbiology 8:237249.

15. Hod, I.; K. Perk; T.A. Nobel y V. Klopfer. 1972. Lung carcinoma of sheep (Jaagsiekte). III. Lymph node, blood and immunoglobulin. J. Nat. Can. Inst. 48:487-507.

16. Hoffmann-Fezer, G. J. Thum; C. Ackley; M. Herbold; J. Mysliwietz; S. Thefeld; K. Hartmann y W. Kraft. 1992. Decline in CD4+ cell numbers in cats with naturally acquired feline immunodefiency virus infection. J. of Virology 66:1484-1488.

I7. Jassim, F.A.; J.M. Sharp y P.D. Marinello. 1987. Three-step procedure for isolation of epithelial cells from lungs of sheep with Jaagsiekte. Res. Vet.Sc., 43: 407-409.

18. Lairmore, M.D.; R.H. Rosadio y J.C. DeMartini. 1986. Ovine lentivirus lymphoid interstitial pneumonia: Rapid induction in neonatal lambs. Am. J. Pathol. 125:173:181.

19. Leslie, C.C.; K. McCornick; J.L. Cook y R.J. Mason. 1985. Macrophages stimulate DNA synthesis in rat type II 
alveolar cells. Am. Rev. Respir. Dis. 132:1246-1252.

20. Luján, L.; L. Begara; D. Collie y N. Watt. 1993. Phenotypic analysis of cells in bronchoalveolar lavage fluid and peripheral blood of maedi visna-infected sheep. Clin.Exp. Immunol $91: 272-276$

21. Mackay, R.C. 1988. Sheep leukocyte molecules: a review of their distribution, structure and possible function. Vet. Immunol. Immunopath. 19:1-20.

22. Myer, M.S.; D.W. Verwoerd y H.M. Garret. 1987. Production of a macrophage chemotactic factor by cultured jaagsiekte tumour cells. Onderstepoort J. Vet. Res. 54:9-15.

23. Nelson, D.S.; M. Nelson y Y. Inoue. 1985. Some aspects of macrophagetumor relationships. In S. Reichard and M. Kojima (Eds), Macrophage biology. Alan R. Liss. Inc. New York, pp833-844.

24. Ouzrout, R.; F. Guiguen y C. Lerondelle. Evolution des souspopulations lymphocytaires dans le lait de brebis au moment de l'excrétion du virus maedi. 1991. Annales de Recherches Vétérinaires, 22(4):379-386 Ecole Nationale Veterinaire.

25. Palmarini, M.; M. Holland; C. Cousens; R. Dalziel y M. Sharp. 1996. Jaagsiekte retrovirus establishes a dissseminated infection of the lymphoid tissues of sheep affected by pulmonary adenomatosis. J.General Virol. 77 :29912998

26. Rosadio, R.H.; J.M. Sharp; M.D. Lairmore; J.E. Dahlberg y J.C. DeMartini. 1988a. Lesions and retroviruses associated with naturally occurring ovine pulmonary carcinoma (sheep pulmonary adenomatosis). Vet Pathol 25:58-66

27. Rosadio, R.H.; D.M. Lairmore; I.H. Russell y J.C. De Martini. 1988b. Retrovirus associated ovine pulmonary carcinoma (sheep pulmonary adenomatosis) and lymphoid interstitial pneumonia. I. Lesion development and age susceptibility. Vet Pathology 25:475478.
28. Rosadio, R. 1991. Chronic respiratory diseases in Peruvian sheep. Proocedings of the sheep Veterinary Society $15: 81$ 85.

29. Scott, P. y S.H.E. Kaufmann. 1991. The role of T-cell subsets and cytokines in the regulation of infection. Immunol. Today 12:346:348.

30. Semenzato, G. 1991. Immunology of insterstitial lung diseases: cellular events taking place in the lung of sarcoidosis, hypersensitivity pneumonitis and HIV infection. Eur. Resp. J. 4:94-102.

31. Sharma, R.; Z. Woldehiwet; D.G. Spiller y H.M. Warenius. 1990. Lymphocyte subpopulations in peripheral blood of experimentally infected with bovine respiratory syncytial virus. Vet. Immunol. Immunopath. 24:383-391.

32. Sharma, R. y Z. Woldehiwet. 1991. Cytotoxic $\mathrm{T}$ cell responses in lambs experimentally infected with bovine respiratory syncytial virus. Vet. Immunol. Immunopath. 28:237-246.

33. Sharp, J.M.; K.W. Angus; E.W. Gray y F.M. Scott. 1983. Rapid transmission of sheep pulmonary adenomatosis (Jaagsiekte) in young lams. Arch Virology 78:89-95.

34. Sharp, J.M. 1987. Sheep pulmonary adenomatosis: a contagious tumour and its causes. Cancer survey 6:73-83.

35. Sharp, J.M. y Angus, K.W. 1990. Sheep pulmonary adenomatosis: clinical, pathological and epidemiological aspects. In Maedi-Visna related diseases. G. Petursson and Hoff-Jorgensen (Eds). Kluwer Academic Publishers. Boston/ Dordrech/London. pp 157-175.

36. Wesselius, L.J.; L.J. Manahan-Wahl; S. Sherard y N.A. Abdou. 1985. Tlymphocyte subsets in blood and bronchioalveolar lavage (BAL) fluid from patient with bronchogenic carcinoma. Am. Rev. Respir. Dis. 131:A13.

37. Zouali, M. 1995. B-cell superantigens :Implications for selection of the human antibody repertoire. Immunol Today. 16(8) : 399-405. 